\title{
O POVO DO MEL, A PRAIA E O MATO
}

\section{Iyalorixá Michele de Oxum}

Camila Hein

Edgar Rodrigues Barbosa Neto

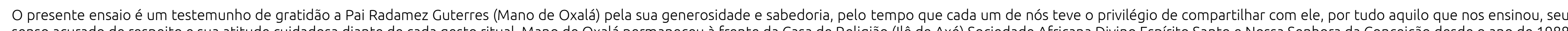

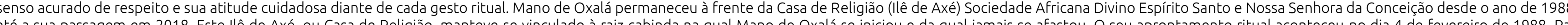

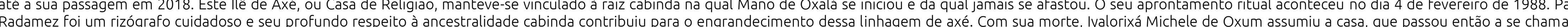
Radamez foi um rizógrafo cuidadoso e seu profundo respeito à ancestr

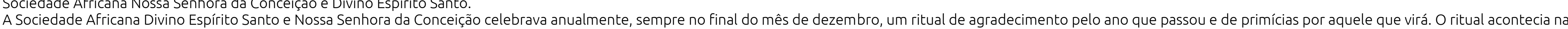

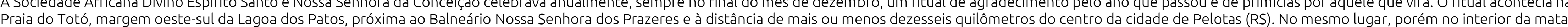
um outro ritual, entre os meses de abril e maio, era oferecido ao orixá Ogum. As fotos abaixo correspondem a esses dois rituais, ambos ocorridos no ano de 2010, respectivamente nos meses de maio e dezembro.

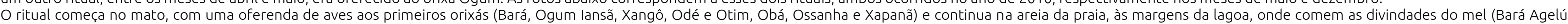

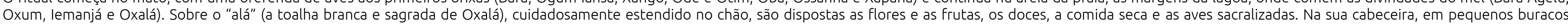
escavados na areia, acendem-se algumas velas, as quais, juntamente com um lampião a gás, garantem o ponto de luz em cujo contorno se forma a roda dos dançantes.

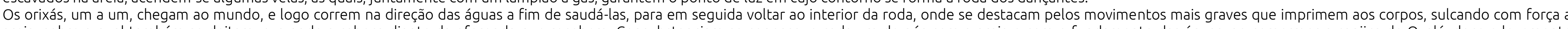
areia, sobre a qual tambêm se deltam, curvando a caça dinte da oferenda que recebem. Co

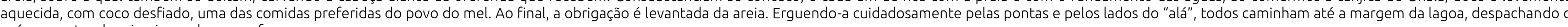
axé nas costas da primeira onda que se forma.

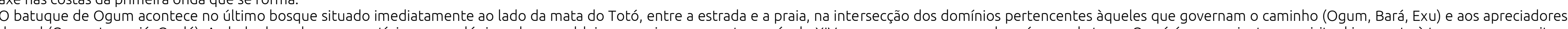

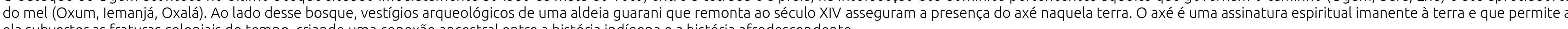
la subverter as fraturas coloniais do tempo, criando uma conexão ancestral entre a história indígena e a história afrodescendente. 


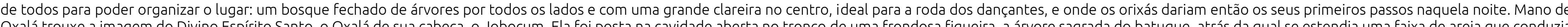

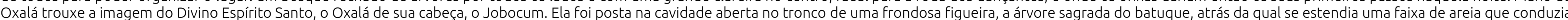
até as águas da Lagoa dos Patos.

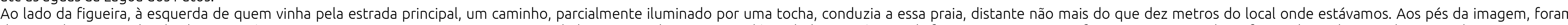

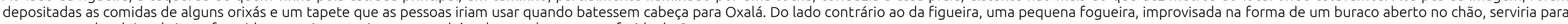
assar a carne dos dois cabritos oferecidos na noite anterior, mas também da costela, carne preferida de Ogum.

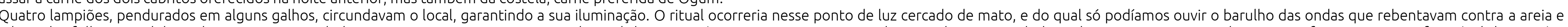

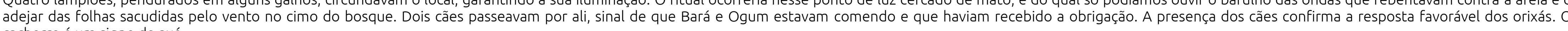
cachorro é um signo do axé.

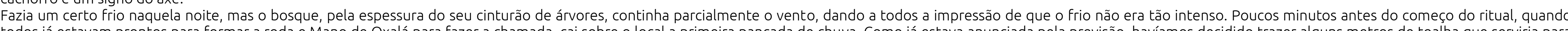

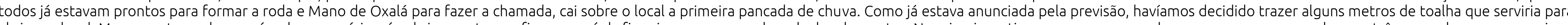

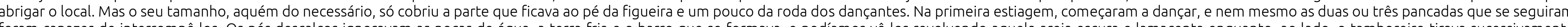

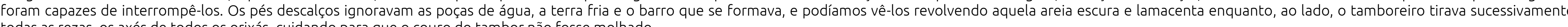
todas as rezas, os axés de todos os orixás, cuidando para que o couro do tambor não fosse molhado.

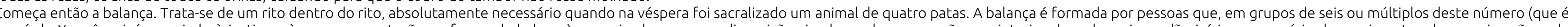

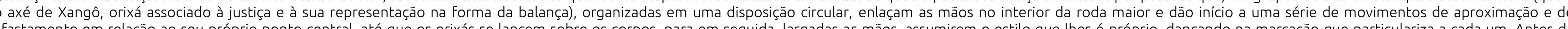
os, para em seguida, largadas as mãos, assumirem o estilo que thes é próprio, dançando na marcação que particulariza a cada um. Antes da

a viamos os orixás dançar, enquanto à sua volta, com passos mais lentos, continuavam os humanos, no seu ritmo mais humano. O axé gosta do barro e da chuva, da praia e do mato. São seus signos também. 

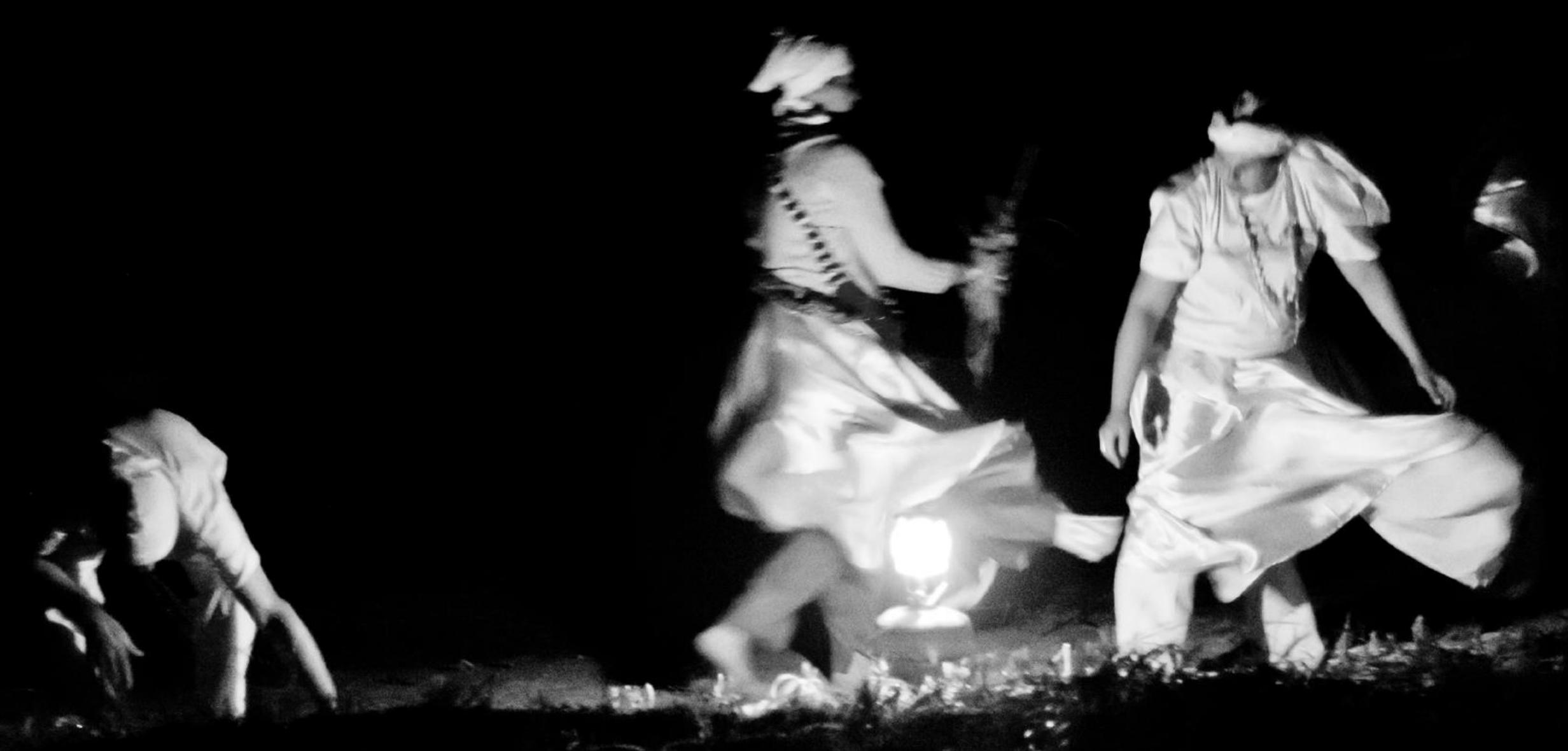

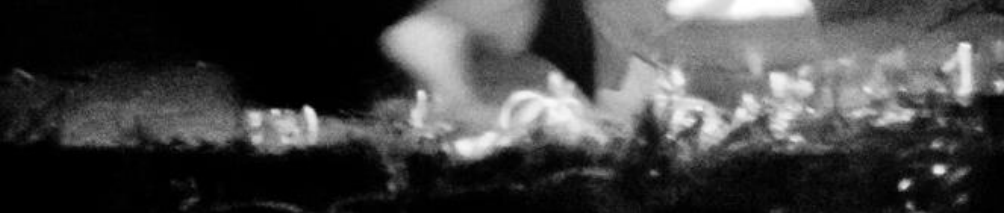

s. 
है?

(2)

,

ha

5

(x)

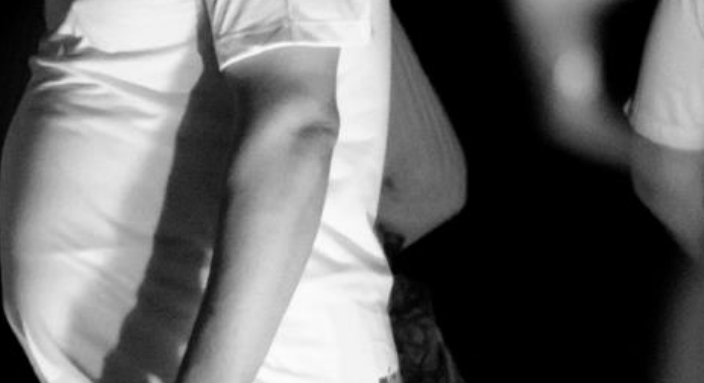




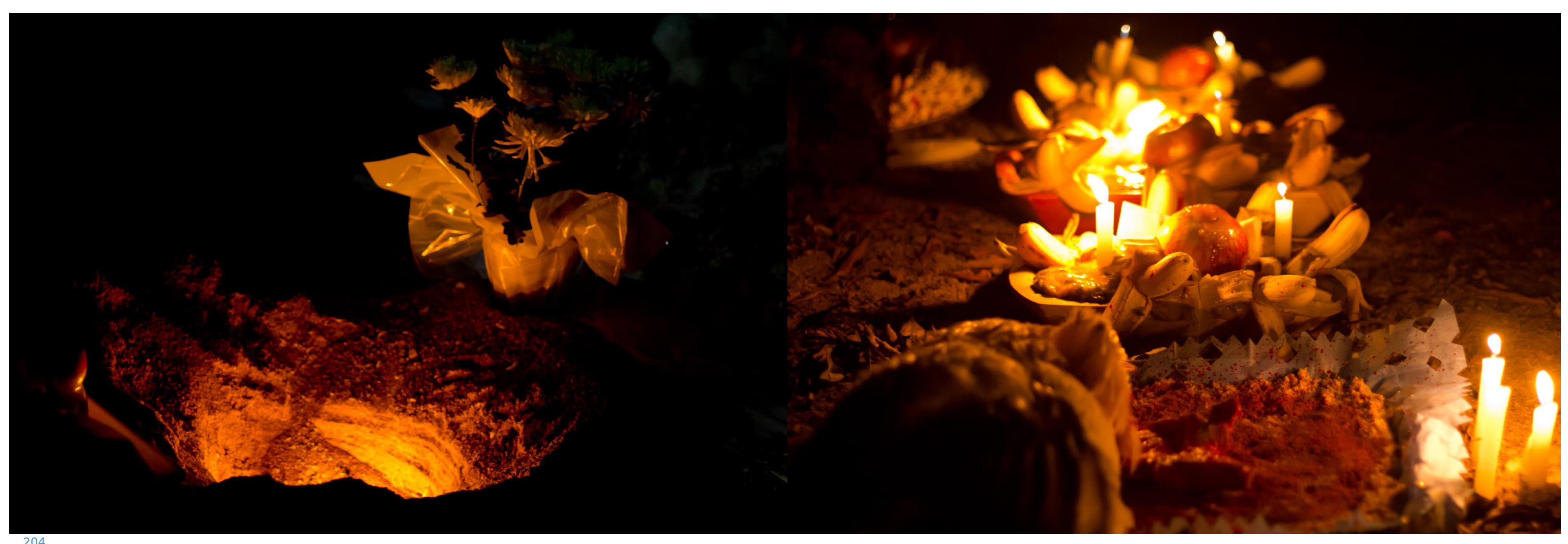




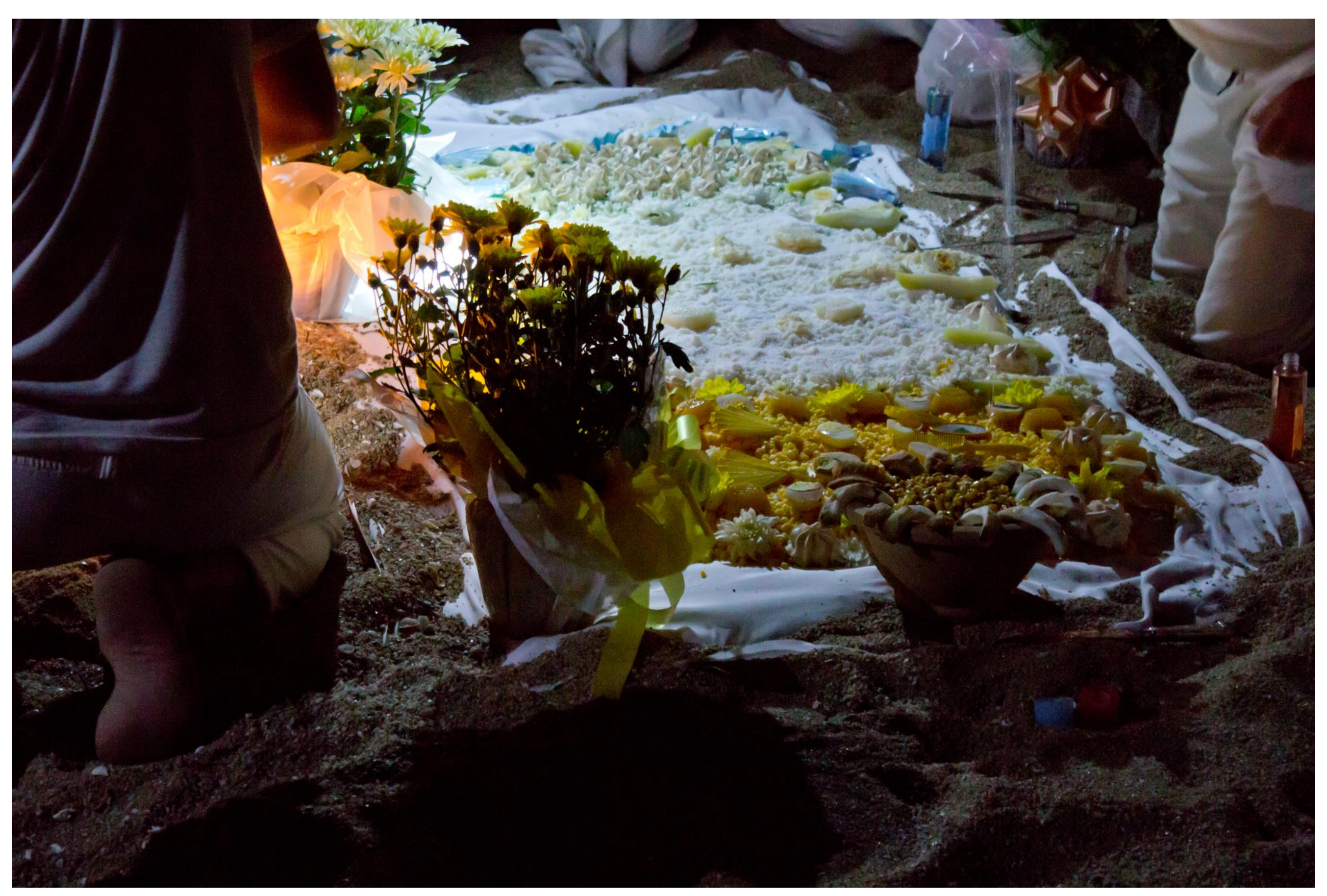




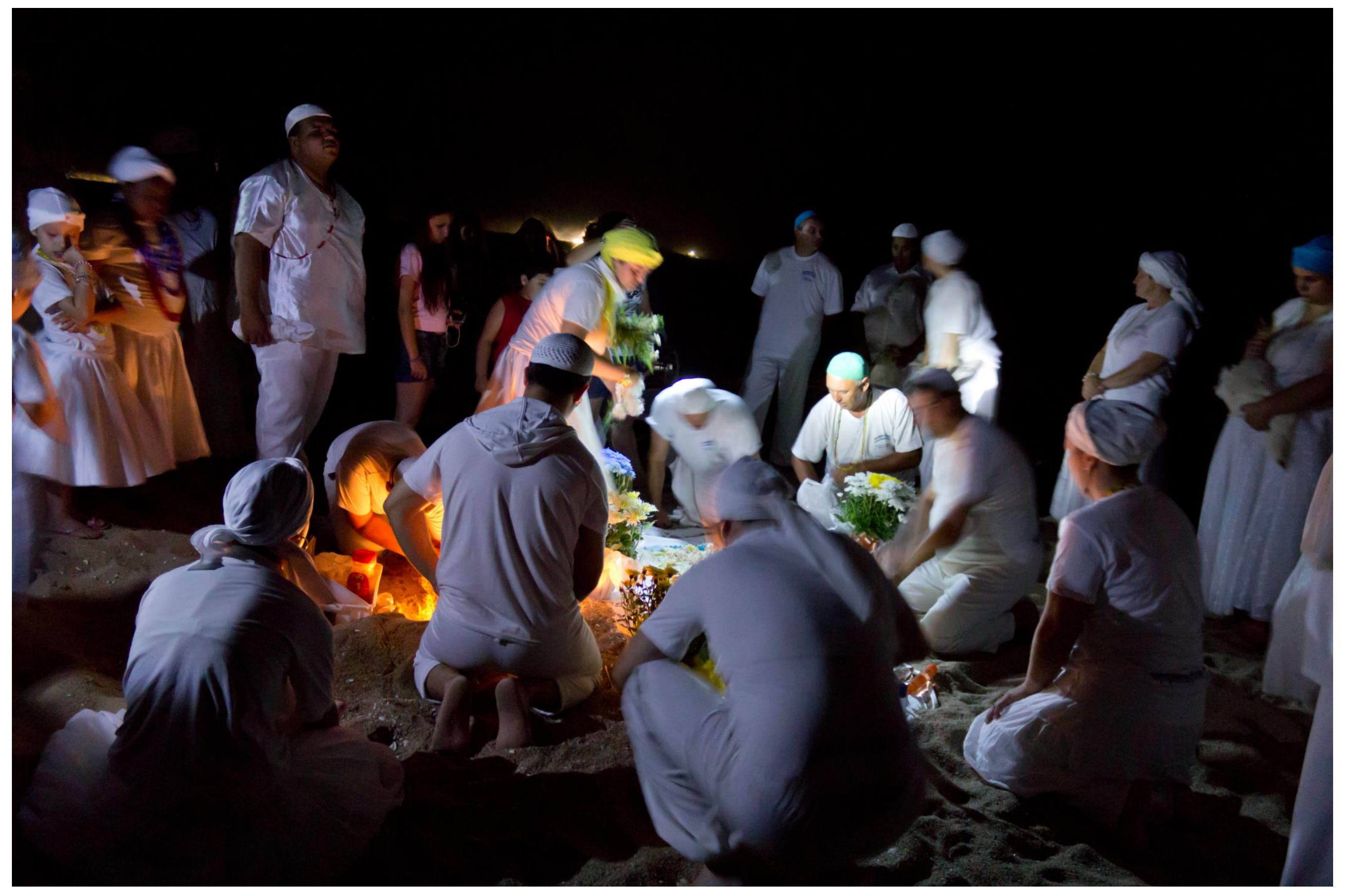




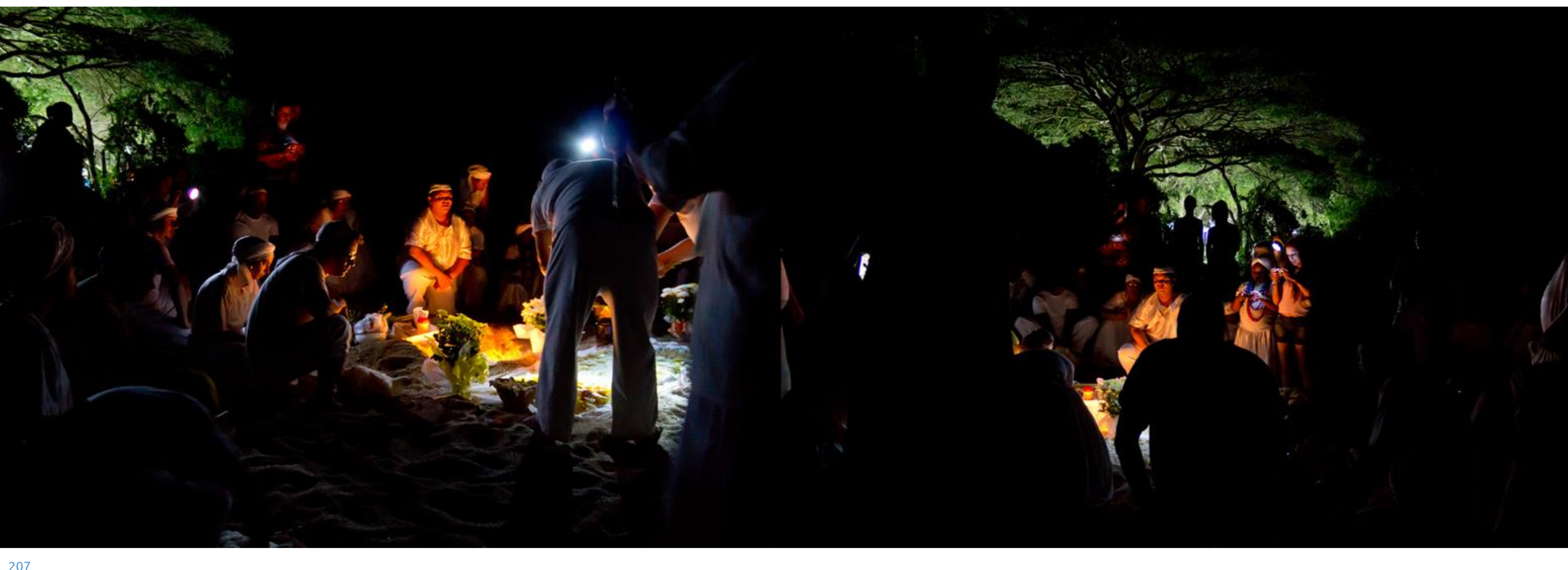




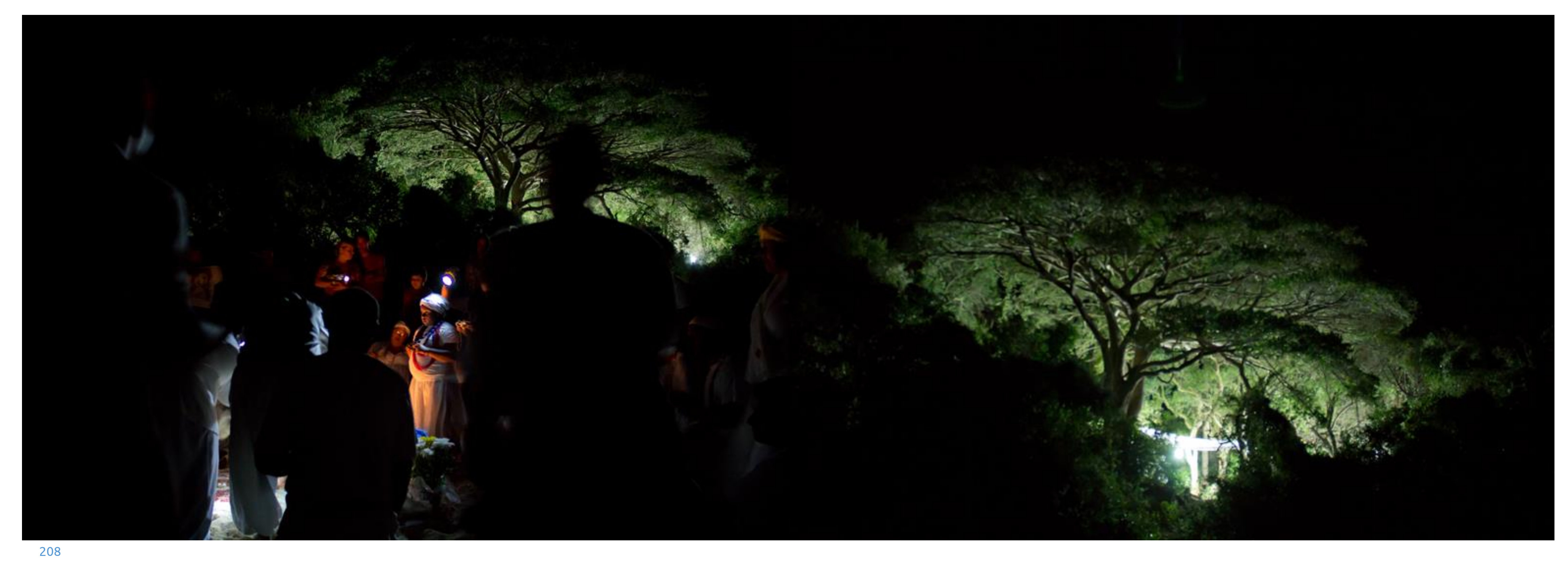




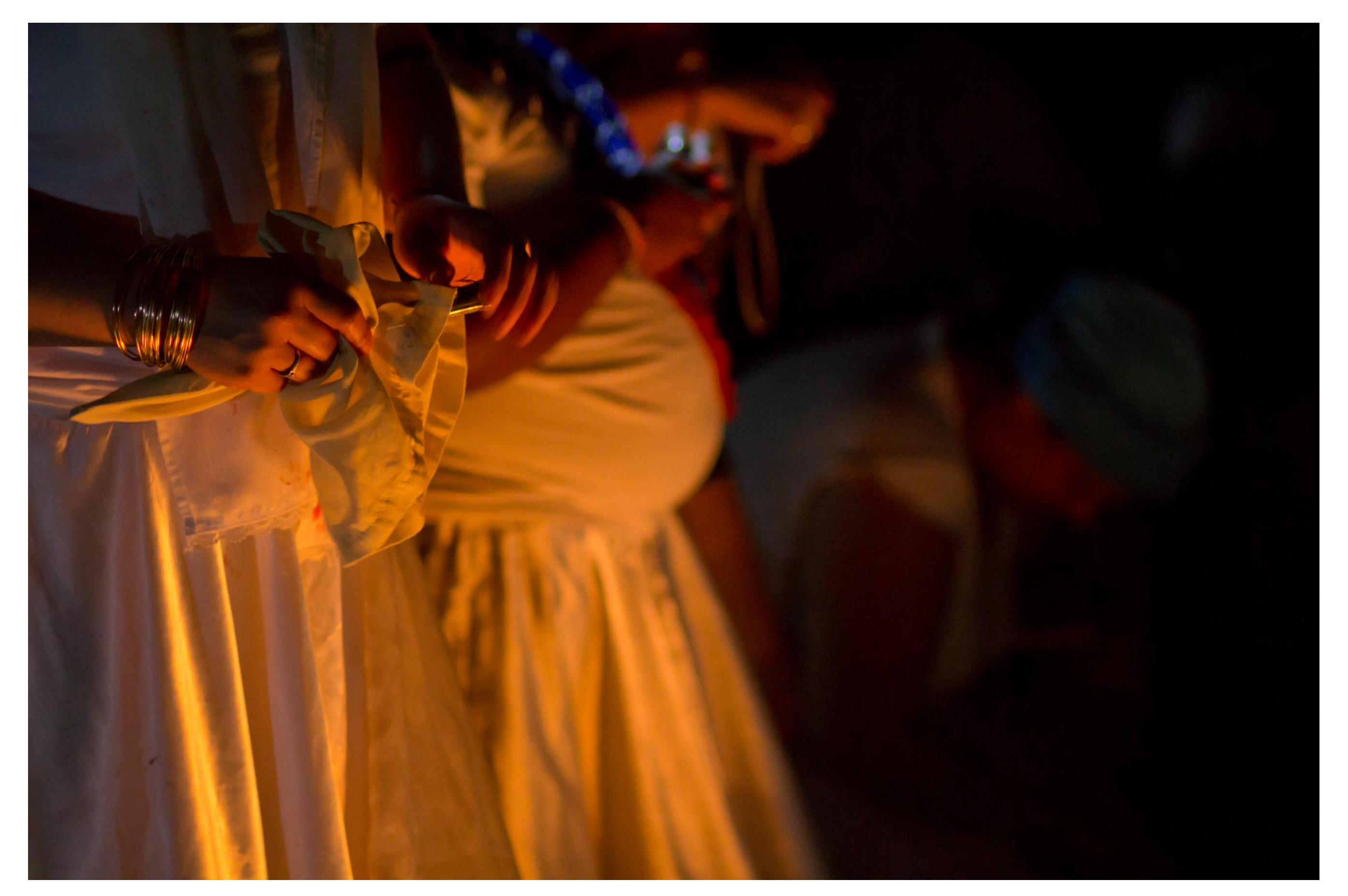




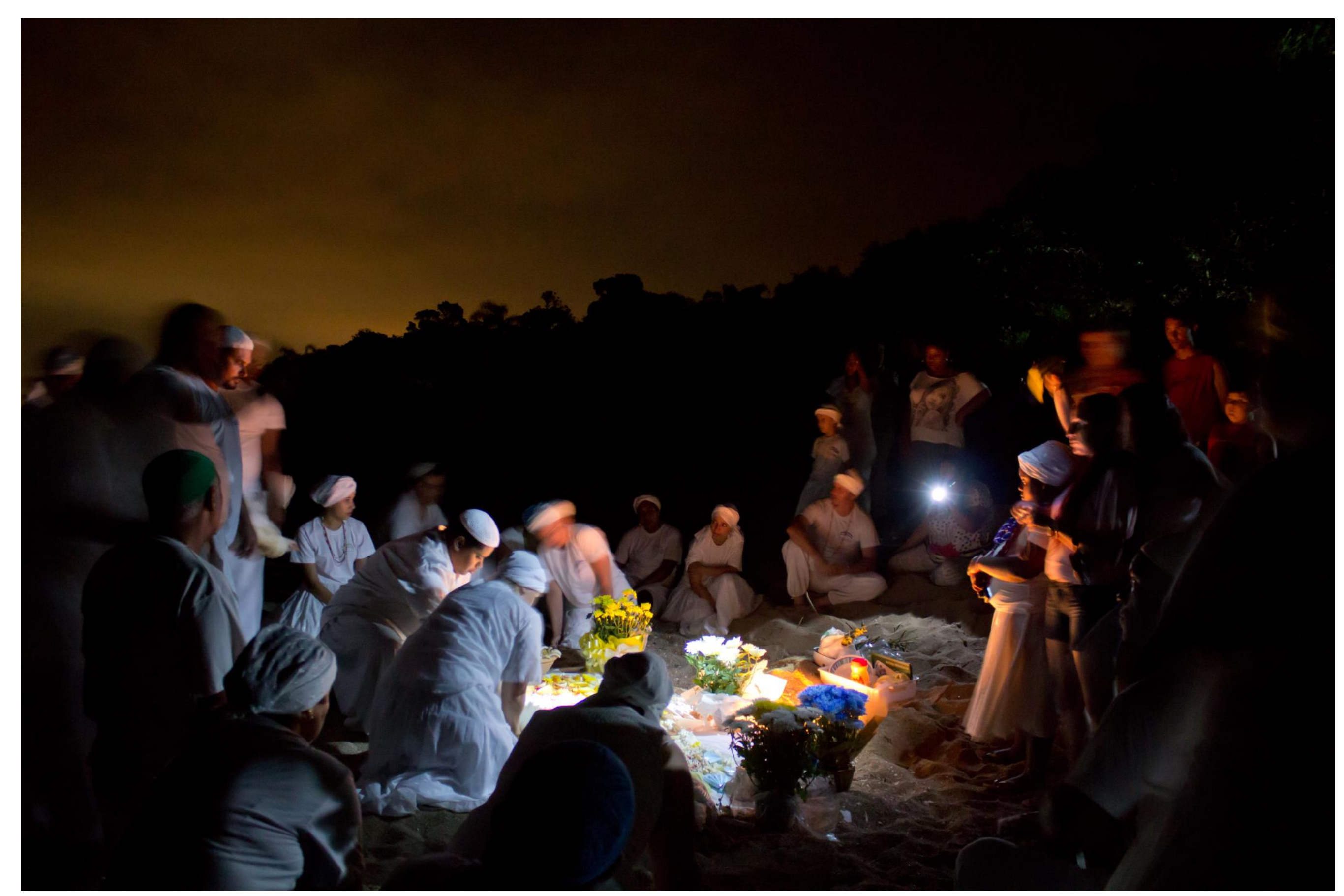




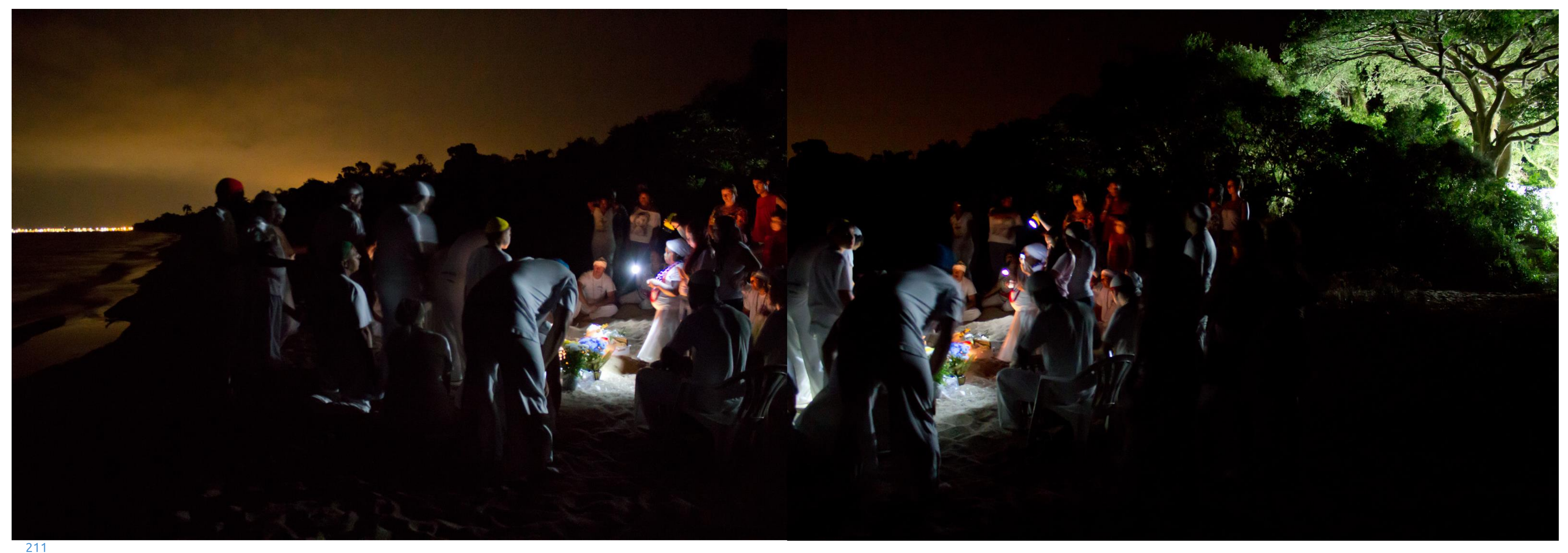




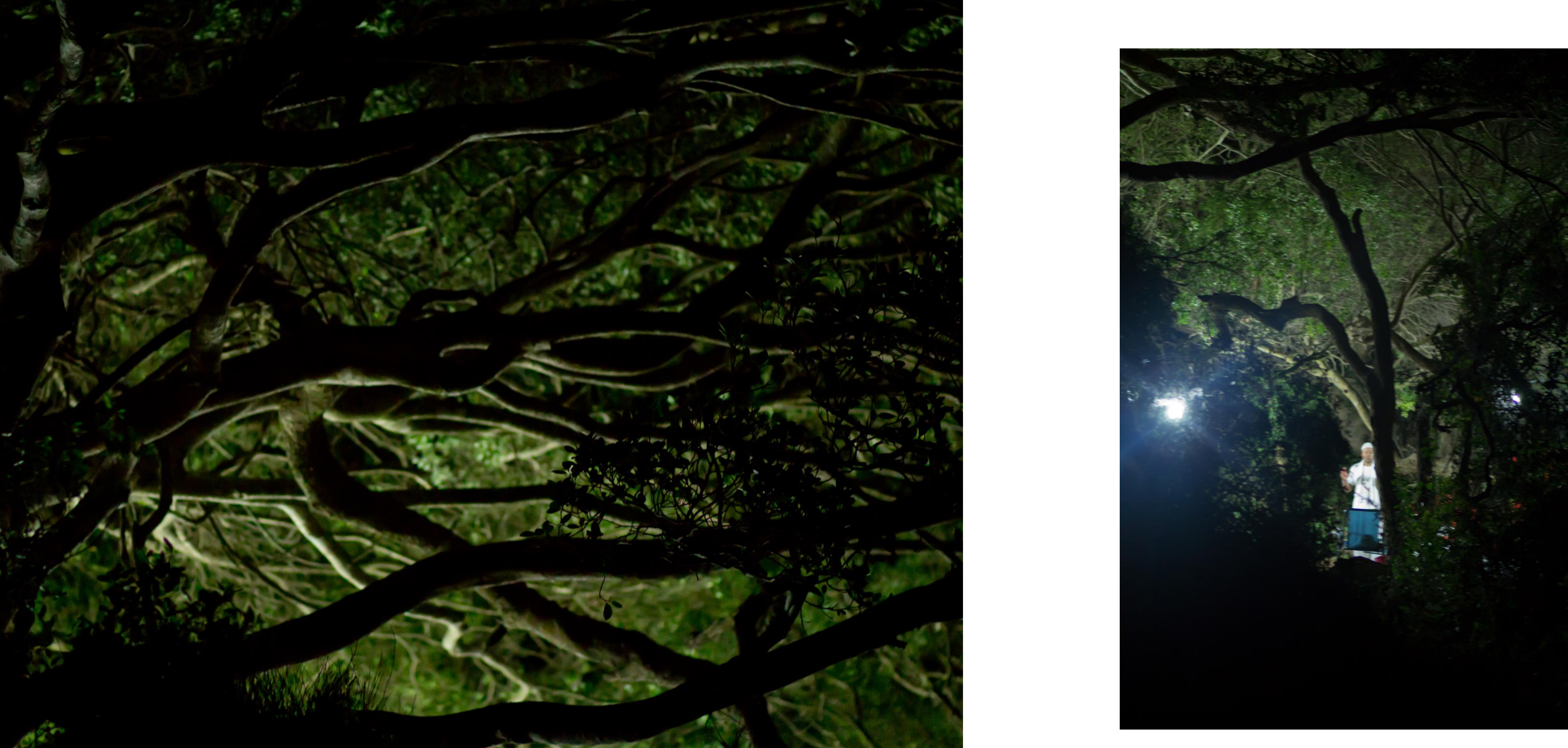


